\title{
POTENTIAL OF SENSOR-BASED SORTING IN ENHANCED LANDFILL MINING
}

\author{
Bastian Küppers ${ }^{1, *}$, Juan Carlos Hernández Parrodi ${ }^{1,2}$, Cristina Garcia Lopez ${ }^{3}$, Roland \\ Pomberger ${ }^{1}$ and Daniel Vollprecht ${ }^{1}$
}

${ }^{1}$ Montanuniversität Leoben, Franz-Josef-Strasse 18, Leoben 8700, Austria

${ }^{2}$ Renewi Belgium SA/NV, NEW-MINE project, Gerard Mercatorstr. 8, 3920 Lommel, Belgium

${ }^{3}$ RWTH Aachen University - Institut für Aufbereitung und Recycling, Wüllnerstrasse 15, Aachen 52062, Germany

Article Info:

Received:

27 May 2019

Revised:

26 July 2019

Accepted:

19 August 2019

Available online:

23 December 2019

Keywords:

Enhanced Landfill Mining

Sensor-based Sorting

NIR Spectroscopy

\begin{abstract}
In landfill mining, simple technologies and processing chains are frequently applied to excavated material in order to extract recyclable metals and high-calorific fractions used in energy recovery. Sensor-based sorting is one way to extract more and better material from a landfill. Two testing series have been performed using stateof-the-art technology to assess the technical feasibility of classifying and sorting landfill material with the aid of near-infrared spectroscopy. Fractions were classified as inert and combustible and sorted by particle sizes ranging from $90-30 \mathrm{~mm}$, from $30-10 \mathrm{~mm}$ and from $10-4.5 \mathrm{~mm}$ for water content levels of $0 \mathrm{wt} \%$ and of 15 wt\%, respectively. Additional tests were applied different landfill mining materials. Polypropylene (PP), polyethylene (PE) and polyvinyl chloride (PVC) products were produced, using sensor-based sorting, from a mixed fraction of particle sizes ranging from $60-200 \mathrm{~mm}$. Both test series applied air-classified heavy fractions gained from two distinct processing schemes of landfill mining projects in Belgium and in Austria. Results show that the separation and classification of inerts and combustibles is feasible, enriching inert fractions with purities of $97.7 \mathrm{wt} \%$ to $99.6 \mathrm{wt} \%$ derived from inputs whose inert contents achieved 85.6 to $98.8 \mathrm{wt} \%$. Efficient sorting is a function of the level of pre-processing, water content, relative amounts of adhesive fines, input composition and particle size ranges of the input material. Results from the second test series show that PP, PE, PVC and other materials can be successfully distinguished, achieving correct classification and ejection into respective product fractions of $91.8-99.7 \mathrm{wt} \%$.
\end{abstract}

\section{INTRODUCTION}

In the past, landfills were considered cost-effective and final means of waste disposal (Krook et al., 2012). Nowadays such landfills pose both a problem and a chance. Spatial constraints, landfill-based hazards like leachate and methane emissions (Danthurebandara, M. et al., 2015) and shortage of landfill volume (Wörrle, J., 2018) can be arguments in favour of landfill mining (LFM) activities (Quaghebeur et al., 2013, Mor et al., 2006, Sormunen et al., 2008).

LFM is usually expensive and not economically feasible. Economic feasibility could be achieved, however, by using mechanical processing to recover marketable valuable materials. Since the 1950 s, LFM projects have mostly applied simplified process chains using a screening stage and optional subsequent air classification and magnetic separation, among other processes, to render mechanical processing as cost-effective as possible (Krook, J. et al., 2012). As a consequence, only limited amounts of landfill resources (metals and refuse-derived fuel (RDF) could be recovered in the past (Krook et al., 2012). This limitation may be due to the fact that the reduction of environmental impacts and landfill remediation commonly has been given preference to the recovery of land or of landfill volume (Danthurebandara et al., 2015).

By contrast, the design of enhanced landfill mining (ELFM) is targeting the extraction of valuable materials for recycling (waste-to-material, WtM) and for energy production (waste-to-energy, WtE). The TönsLM project, for instance, has developed and examined scenarios based on rather complex process chains and innovative technologies. In addition to comminution, ballistic separators, screening and magnetic separation, also eddy current separators and near-infrared (NIR) sorters were considered in processing (Breitenstein et al. 2016), enabling higher and 
purer yields of recyclables. This resulted in better market prices, facilitating economically improved mining.

Studies have shown that ELFM is mainly inspired by the recovery of landfill volume and by the extraction of metals and of high-quality combustible fractions (Danthurebandara et al., 2015, Jones et al., 2013, Kieckhäfer et al. 2017). Most published ELFM projects so far are still at the planning stage, however. One main caveat of any practical implementation of (E)LFM projects is the risk that expected costs may exceed the achievable profit (Kieckhäfer et al. 2017). If framework conditions for ELFM should change, the mining of landfills will become more attractive to landfill operators (Kieckhäfer et al., 2017). This paper intends to shed more light on the potential recovery of recyclable and energetically valuable materials.

Utilization of the high-calorific fraction derived from (E) LFM has been practically tested in the recent past (Rotheut and Quicker, 2017; Wolfsberger et al., 2015). The relative amount of heavy metals contained in a high-calorific fraction limits its use in Austrian co-incineration plants (Wolfsberger et al., 2015). Since the distribution of heavy metals in the individual groups of substances and particle size ranges may vary significantly, suitable pre-treatment (separation of fractions contaminated with heavy metals) can prevent exceeding the limit values (Wolfsberger, T. et al, 2015, García López, C. et al., 2018).

Studies of Rotheut, M. and Quicker, P. (2017) concerning the energetic utilisation of RDF from LFM have shown that also the RDF's properties may vary a lot, affecting in particular calorific value, water and ash contents. Material from the 'Pohlsche Heide' landfill was excavated, for example, and processed in a state-of-the-art mechanical-biological waste treatment plant. Once the metals had been removed, the light fraction recovered using air classification was thermally converted into RDF. Calorific values between 9.2 and $23.9 \mathrm{MJ} / \mathrm{kg}$, ash contents of up to $49.6 \%$ and water contents of $9.1 \%$ to $30 \%$ were observed. These findings as well as the sometimes high chlorine content caused the fuel properties of the examined material to be ranked as troubling.

Regarding mono-combustion of high-calorific fractions from LFM, the relative amounts of $\mathrm{HCl}$ and $\mathrm{SO}_{2}$ included in the raw gas have been observed to exceed customary process values. In addition, the generation of steam has varied strongly while the bottom ash has shown finer particle size distributions and increased contents of $\mathrm{Cl}$ in the eluate. In clean gas, the only elevated readings related to the relative amount of $\mathrm{HCl}$. Based on these and further experiments the authors conclude that co-combustion of RDF from LFM with RDF from municipal solid waste (MSW) in a 1:1 ratio seems feasible while mono-combustion of non-pre-treated material remains troubling (Rotheut and Quicker, 2017).

Mechanical recycling and other options, such as gasification, pyrolysis and hydrogenation, can only be pursued if more elaborate pre-treatment (cleaning, drying, comminution and thorough sorting) takes place (Zhou et al., 2014). The waste-to-energy (WtE) route is expected to be a plausible method of utilising high-calorific fractions from (E)LFM (García López et al., 2018; Quaghebeur et al., 2013) while a waste-to-material (WtM) route is not considered promising due to the increased levels of contaminants in recyclables (Quaghebeur et al., 2013). Generating potential RDF (pRDF) of a quality sufficient for (co-)combustion from (E) LFM requires the separation of material classes containing contaminants like PVC (chlorine), minerals (increased ash content) and metals.

Compared to the calorific fractions, recycling inert constituents such as metals, glass, ceramics and stone is estimated to be more promising (Quaghebeur et al., 2013). Mechanical processing, e.g. the separation of wood, paper and plastics from inerts, is required in this case, either to reduce the $\mathrm{TOC}$ or the $\mathrm{Cl}$ content of fractions intended for construction aggregates.

Sensor-based sorting (SBS) can be utilised to separate impurities from the respective fractions ( $p R D F$ and inert) in order to comply with the boundaries of both the high-calorific fraction and the inert fraction. One promising approach is the treatment of 3D or heavy fractions derived from air classification or ballistic separation. Generating suitable products from an ELFM process may require carrying out not only single but also multi-stage sorting steps (cascading application of SBS technology). In this way, several types of plastics can be separated, resulting in pure product fractions. Near-infrared technology was found helpful both for distinguishing inert from pRDF and for differentiating types of plastic that then could be separated using compressed air blasts (Kieckbehäfer et al., 2017; Beel, 2017).

Flawless functioning of SBS units is achieved by pre-treating LFM material. An important step of preconditioning is drying the landfill material, hopefully to improve subsequent mechanical processing (García López et al., 2018). Contaminants such as fine adhesions and coarse particles should be separated and fractions of processable particle size ranges produced using pre-classification. The resulting particle size ranges have to match machine requirements of subsequent processing units. In addition, this classification can be used to subdivide the material flow into volume and mass flows suitable for further treatment, preventing overloading of the downstream processing equipment. Pre-processing can also be used to enrich the valuable substances or to separate contaminants into specific grain size ranges and material flows (Pretz and Julius, 2008).

If the treatment is carried out on a landfill site, SBS technology must be adapted to adverse environmental conditions. The treatment can be affected by weather conditions or by dust, raising the risk of e. g. soiling on light bulbs that would cause malfunction or impairment of the SBS equipment (Gundupalli et al., 2017).

This paper discusses near-infrared-(NIR)-based sorting since this technology provides a wide range of possible applications. However, NIR sensors can only analyse the surface of particles and are therefore particularly susceptible to external contamination and adhesions (Pomberger and Küppers, 2017). That is why research regarding the application of this technology in LFM is of particular interest. Two applications for NIR SBS technology are examined:

- Enrichment of the inert fraction using the separation of 
combustibles (plastics, paper, cardboard, wood, etc.); - Distinction and separation of various types of plastic from a LFM process to create unpolluted fractions.

To verify the technical feasibility of these applications, the distinctness of combustibles, inerts and impurities is examined and quantified.

\section{MATERIALS AND METHODS}

ELFM projects were conducted at Mont-Saint-Guibert (MSG), Belgium, and on the Halbenrain landfill, Austria. Excavations and mechanical processing in MSG were carried out to verify the suitability of a ballistic separator as the first processing unit in the mechanical processing of LFM material. In Halbenrain, the purpose of on-site examinations was to test whether the available mechanical biological treatment plant was able to process LFM material.

At the MSG landfill, municipal solid waste (MSW) and construction and demolition (C\&D) waste were disposed of between 1958 and 1985. For the purposes of this examination, the top clay layer was removed first. Next, a total of about $425 \mathrm{~m}^{3}$ of landfill material was excavated in four batches and treated with the ballistic separator (STADLER STT 6000). The LFM material was processed in two stages, using mesh sizes of $200 \mathrm{~mm}$ and $90 \mathrm{~mm}$ to produce five output streams (cf. Figure 1). Detailed information concerning landfill site, processing, sampling and landfill composition is provided by García López et al. (2019) and Hernández Parrodi et al. (2019).

The fine fractions samples $(<90 \mathrm{~mm})$, gained during ballistic separation, were divided into two fractions and treated at two different water content levels ( 0 wt\% and 15 $w t \%)$ or using screening into the grain size ranges of $90-30$ $\mathrm{mm}, 30-10 \mathrm{~mm}, 10-4.5 \mathrm{~mm}$ and $<4.5 \mathrm{~mm}$, followed by air classification. Heavy fractions from air classification (90$30 \mathrm{~mm}, 30-10 \mathrm{~mm}$ and $10-4.5 \mathrm{~mm}$ ) yielded input material for SBS experiments and were therefore drawn on during the examination.

At the Austrian Halbenrain landfill, about $500 \mathrm{t}$ of LFM material were excavated and processed in an on-site mechanical and biological treatment plant in 2016 to study options for RDF and metal recovery. The treatment included
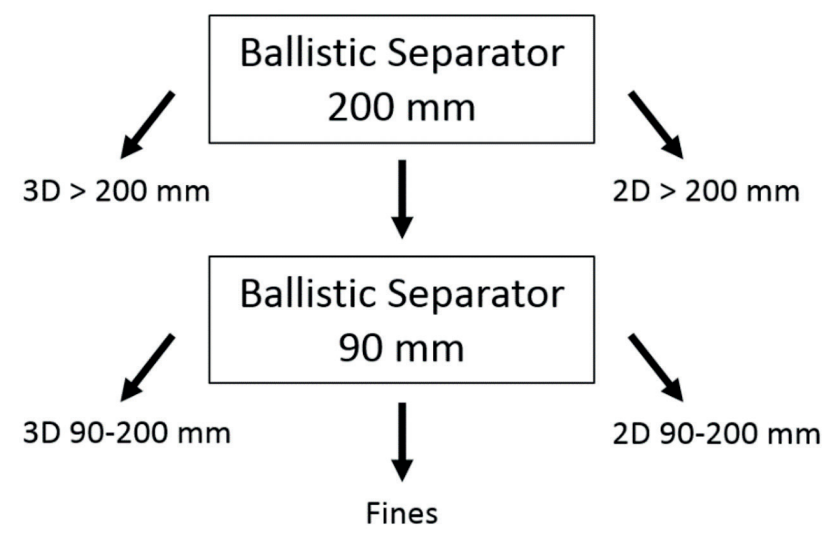

FIGURE 1: Procedure for mechanical treatment of landfill material in MSG. three to four weeks of biological drying in rotting boxes, followed by shredding, multiple screening stages (screen cuts: $200 \mathrm{~mm}, 60 \mathrm{~mm}, 14 \mathrm{~mm}$ ), separation of ferrous and non-ferrous metals using magnetic and eddy current separation and, finally, air classification. More detailed information is provided by García et al., 2018.

For SBS examinations, samples were taken from the heavy fraction of 200-60 $\mathrm{mm}$. These samples were handpicked and all particles (1377 pieces) categorised by visual inspection and Fourier Transformed Infrared Spectroscopy (FTIR, Agilent Technologies, Cary 630) according to material types: polypropylene (PP), polyethylene (PE), polystyrene (PS), polyvinyl chloride (PVC), polyethylene terephthalate (PET), and residuals.

A hyperspectral imaging (HIS) near-infrared chute sorter (sensor: EVK HELIOS NIR G2 320, spectral range 990$1700 \mathrm{~nm}$ ) was used for performing the SBS experiments. The spectral resolution of the sensor was $3.18 \mathrm{~nm}$, its spatial pixel width being $1.60 \mathrm{~nm}$. The frame rate of the line sensor was $476 \mathrm{~Hz}$ for an exposure time of $1800 \mu \mathrm{s}$. During the experiments, the side of a spatial pixel in the direction of movement was always less than $1.6 \mathrm{~mm}$ long. Sorting recipes were created by recording sample objects of each material class. Two recipes emerged:

- Recipe 1 - for treating fractions of $90-30 \mathrm{~mm}, 30-10$ $\mathrm{mm}$ and 10-4.5 mm from MSG (objective: separation of combustible from inert materials of the heavy fractions);

- Recipe 2 - for treating air-classified heavy fractions from the Halbenrain landfill (objective: distinction of plastic types PP, PE, and PVC from PS, PET and residuals).

Recordings of the recipes contained spectra allocated to pixels on all sample objects. Spectra from several pixels were collected and an average spectrum for each material was created. These spectra were used as references for classifying object pixels. The classification of different materials was improved by including only such wavelength ranges that displayed significant differences (cf. Figures 2 and 3). As a result, a pseudo-colour was allocated to each object pixel. All objects were then assigned to the material class represented by the predominant pseudo-colour. Particles were separated using air blasts from a compressed air nozzle bar to validate the sorting efficiency of the recipes. Low throughputs were applied to avoid overlapping objects, allowing to quantify correct classification rates unaffected by variations of the throughput.

The spectra used in recipe 1 are given in Figure 2. In total, 16 spectra of pulp-based materials (wood, paper and cardboard) and bone (red), plastics (green) and inerts (blue) were used for this recipe. Wavelength ranges included in the classification cover $1120-1273 \mathrm{~nm}, 1342-$ $1527 \mathrm{~nm}$ and 1618-1674 nm (areas marked red in Figure 2). Soot-blackened plastics cannot be classified by spectral data reflected in the NIR range since they absorb much of the irradiation. Their classification as plastics was facilitated by using the low intensity of reflected radiation.

For evaluating the results of trials based on recipe 1 , an 


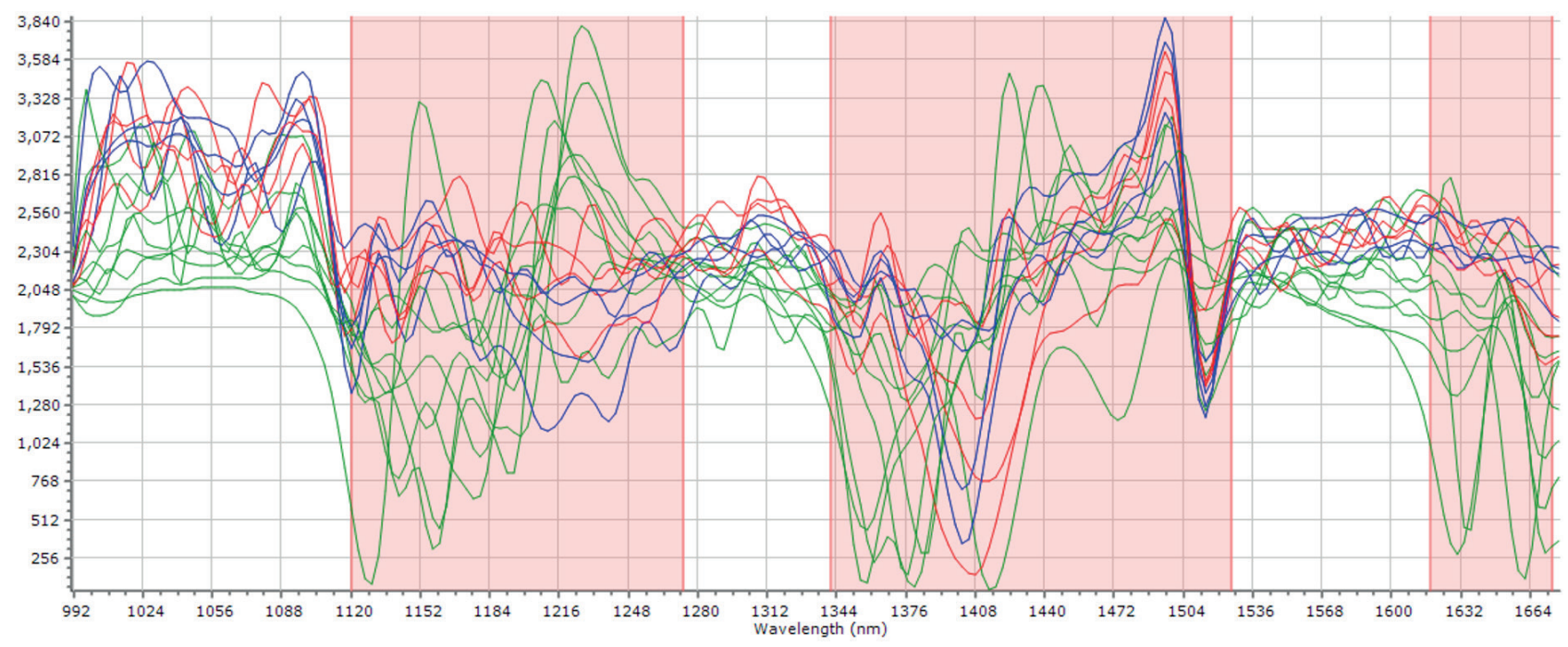

FIGURE 2: Spectral data used to distinguish inerts (blue) and combustibles, consisting of pulp (red) and plastics (green).

enrichment ratio was calculated to assess the separation efficiency of combustibles and inerts. For this purpose, the purity of a product fraction (inert content in inert product or combustibles content in combustibles product) was divided by the content of the respective material class in the input fraction. If the enrichment ratio was 1 or higher, the material class was enriched via sorting.

Spectra used for the constituent separation of PP, PE and PVC from PS, PET and residuals based on recipe 2 are given in Figure 3. In total, 7 spectra of PP (blue), PE (red) and PVC (green) were applied. Wavelength ranges included in the classification cover $1120-1242 \mathrm{~nm}, 1339-1414 \mathrm{~nm}$ and 1636-1671 nm (areas marked red in Figure 3). To prevent erroneous classification of PVC as PP or PE, soot-blackened plastic was always classified as PVC, based on the low intensity of radiation reflected by such particles. Neither spectra of PS nor of PET or residuals were stored in recipe 2.

For assessing the correct classification rates based on recipe 2 , both mass-based (wt\%) and particle-based ( $p \%$ ) approaches were examined. For the mass-based approach, the weight of each material class in the eject and reject fraction entered the calculation of yield by material. For the particle-based approach, the numbers of particles in the eject and reject fractions were counted and entered the calculation of yields by material type in a product. Multiple experiments were performed to reduce the effects of outliers due to atypical positioning and mechanical errors from atypical motions of objects during the sorting process. For each trial, all particles were analysed and sorted anew.

\section{RESULTS AND DISCUSSION}

The results of trials separating inerts and combustibles are given in Table 1. Data on the composition of input and output fractions is given separately for trials based on water contents of $0 \mathrm{wt} \%$ and of $15 \mathrm{wt} \%$. Comparing the composition of all input fractions demonstrates that the inert content rises with decreasing particle size range for both water content levels. Especially material in the frac-

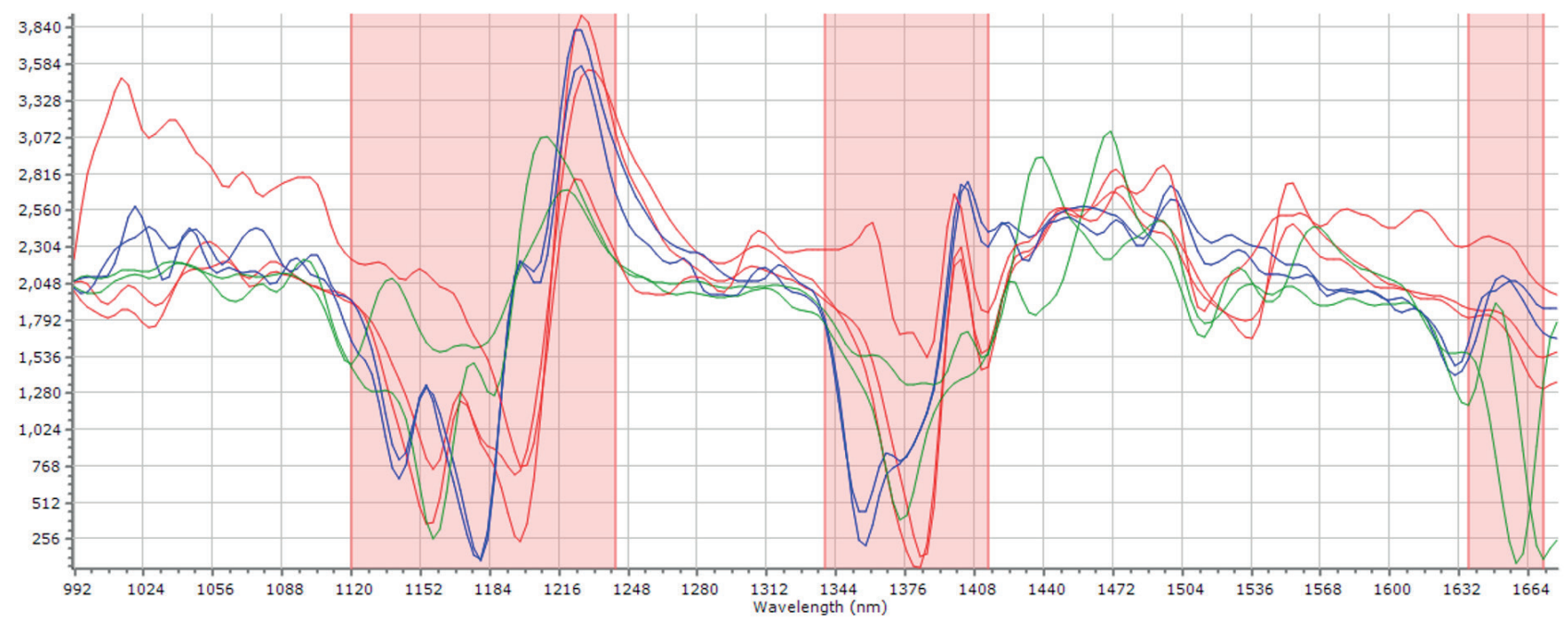

FIGURE 3: Spectral data stored in recipe 2 for distinguishing PP (blue), PE (red) and PVC (green) from PS, PET and residuals. 
TABLE 1: Results of sorting trials with Recipe 1

\begin{tabular}{|c|c|c|c|c|c|c|}
\hline \multirow{2}{*}{$\begin{array}{l}\text { Water Content [wt\%] } \\
\text { Particle size range [mm] }\end{array}$} & \multicolumn{3}{|c|}{0} & \multicolumn{3}{|c|}{15} \\
\hline & $90-30$ & $30-10$ & $10-4.5$ & $90-30$ & $30-10$ & $10-4.5$ \\
\hline \multicolumn{7}{|l|}{ Input } \\
\hline Inert content [wt\%] & 88.2 & 97.1 & 98.1 & 85.6 & 93.7 & 98.8 \\
\hline Combustibles content [wt $\%]$ & 11.8 & 2.9 & 1.9 & 14.4 & 6.3 & 1.2 \\
\hline \multicolumn{7}{|l|}{ Reject - Inert Fractions } \\
\hline Purity - Inert [wt\%] & 99.3 & 99.7 & 98.8 & 99.6 & 97.7 & 99.4 \\
\hline Yield of inerts [wt\%] & 99.7 & 97.8 & 99.0 & 99.8 & 95.1 & 99.5 \\
\hline Enrichment ratio & 1.126 & 1.027 & 1.007 & 1.164 & 1.043 & 1.006 \\
\hline \multicolumn{7}{|l|}{ Eject - Combustibles Fractions } \\
\hline Purity - Combustibles [wt\%] & 62.0 & 26.3 & 36.3 & 68.9 & 31.3 & 49.5 \\
\hline Yield of combustibles [wt\%] & 94.7 & 72.2 & 99.0 & 97.4 & 66.8 & 53.6 \\
\hline Enrichment ratio & 5.254 & 9.069 & 19.105 & 4.785 & 4.968 & 41.250 \\
\hline
\end{tabular}

tion of $90-30 \mathrm{~mm}$ contains significantly more combustibles than material in smaller particle size ranges.

The relative content of combustibles in the input is higher for the water content of $15 \mathrm{wt} \%$ in particle size ranges of 90-30 mm and of $30-10 \mathrm{~mm}$ than in samples containing a water content of $0 \mathrm{wt} \%$. This observation can be explained by higher water absorption in combustibles compared to inerts and increased content of adhesive fines due to the wet surface of combustibles.

All trials achieved high purities for inert fractions (97.7$99.7 \mathrm{wt} \%$ ) while the purity of combustible fractions was comparatively low (26.3-68.9 wt\%). Yet enrichment ratios are low for inert $(1,006-1,164)$ and high for combustibles (4.785-41.250). These results can be attributed to the low content of combustibles in all input fractions, enabling high enrichment ratios, while high inert contents in the input fractions limit enrichment ratios. Rather low purities of combustibles in the respective product fractions can be explained by inert losses wrongly classified and ejected as combustibles. Due to the high amounts of inerts in input fractions, even minor loss of inerts can strongly impact the combustible fractions. The purity of generated combustible fractions could be further improved by applying multiple sorting stages, enriching the combustible fraction even more; the economic feasibility of this approach, however, is in doubt.

The enrichment ratios for inert fractions decrease with particle size while the enrichment ratios of combustibles increase. This is mainly associated with the decreasing relative amount of combustibles in the input for small particle size ranges. For instance, a water content of $0 \mathrm{wt} \%$ produced neither a lesser yield of inerts nor of combustibles for the particle size range of 10-4.5 mm, compared to the sorting results of the $90-30 \mathrm{~mm}$ fraction. Still, the enrichment ratio of inerts drops with decreasing particle size while the enrichment ratio of combustibles rises.

Although a water content of $15 \mathrm{wt} \%$ produces a proportionally lesser yield of combustibles with decreasing particle size, the combustibles enrichment ratio for the particle size range of $10-4.5 \mathrm{~mm}$ is highest at 41.250 , which is more than twice the respective value for a water content of $0 \mathrm{wt} \%$. This is mostly due to the fact that the lower combus- tibles content in the input and the $0.5 \mathrm{wt} \%$ higher yield of inerts for a water content of $15 \mathrm{wt} \%$ have more impact on the sorting efficiency than the yield of combustibles would.

Misclassification, mostly of combustibles but to some extent also of inert, can mainly be referred to faulty classification of pulp material. These particles were characterised by high amounts of adhesive fines on the surface. Such adhesives can impair the spectra, e. g. of paper, resulting in a mixed spectrum of inert and paper. This effect can also be observed in Figure 2 as spectra of pulp-based particles look similar to inert spectra due to their contamination with adhesive fines. The adverse effect of adhesives on SBS is best demonstrated for a water content of $15 \mathrm{wt} \%$, due to increased amounts of adhesives. The yield of combustibles drops with particle size. Especially for the fraction of 10-4.5 $\mathrm{mm}$, major quantities of adhesive fines could be observed on particle surfaces (compare Figure 4).

The sorting results of all trials involving Halbenrain material are given in Table 2. To evaluate the classification and sorting efficiency independently from input composition, only the yield of PP, PE and PVC products is given for each fraction. Results show the average yield of each material class over five runs.

Results of sorting trials show that the particle- and mass-related yields correlate significantly. Differences can be attributed to differing particle masses.

While generating the PP product, neither PVC, PS nor PET were wrongly classified and sorted. Less than $0.8 \mathrm{p} \%$ (0.6 wt\%) of PE and residuals were falsely ejected.

When sorting out the PE product, the primary misclassification observed was that of PP as PE (3.2 p\%/2.1 wt\%) while the ejection of PVC, PS and residuals stayed always below a level of $0.8 \mathrm{p} \%(0.3 \mathrm{wt} \%)$, partly due to gliding particles (PS). No misclassification of PET was observed.

While producing the PVC product, an increased misclassification of PP (4.4 p\%/2.7 wt \%), PE (11.0 p\%/8.8 wt\%) and residuals ( $5.1 \mathrm{p} \% / 3.5 \mathrm{wt} \%$ ) was observed which can be attributed to the classification of soot-blackened particles as PVC. No PET was misclassified and discharged as PVC.

An overall distinction between plastic types and separation of such material fractions from LFM could be per- 


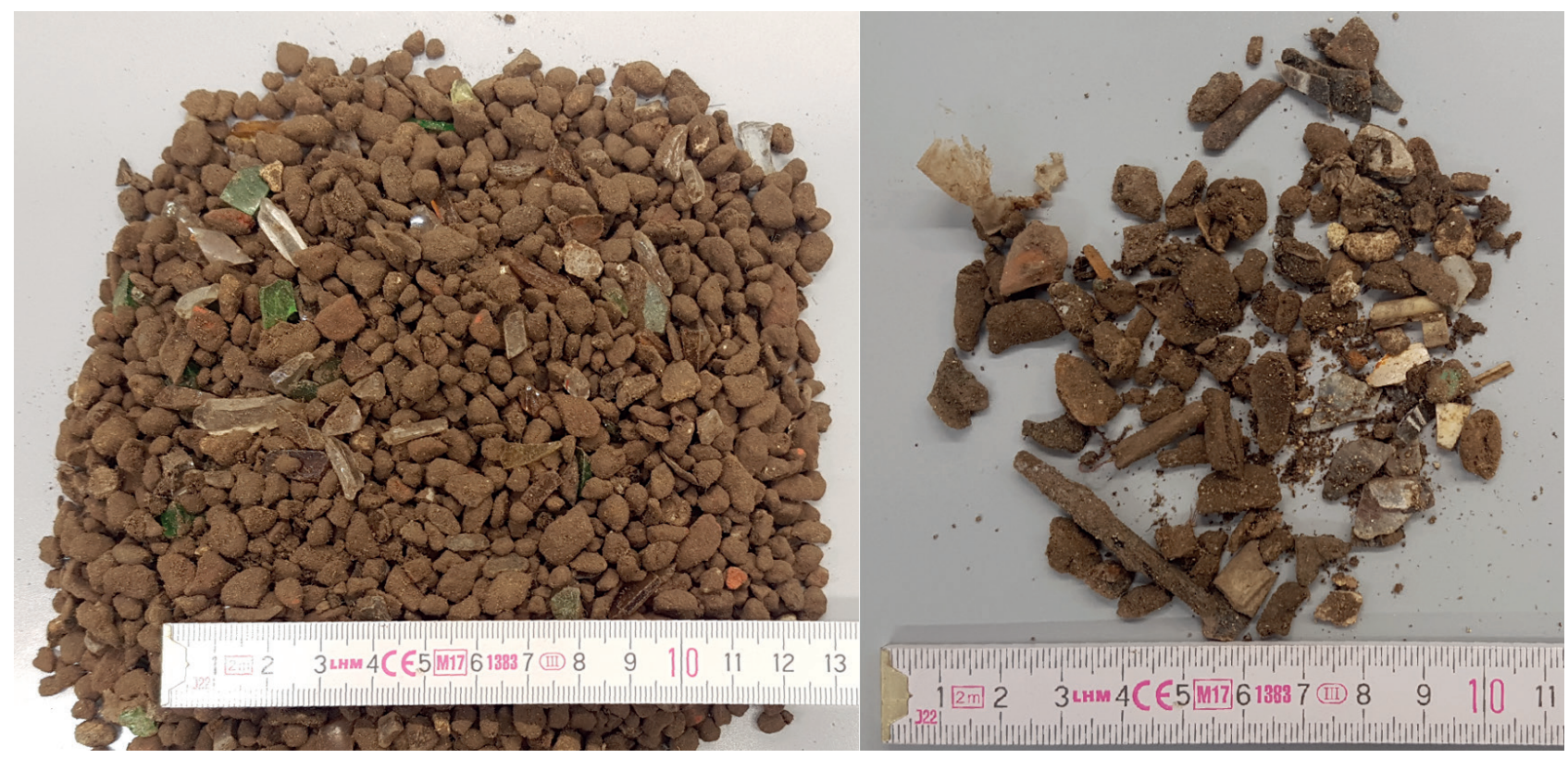

FIGURE 4: Reject (left) and eject (right) from SBS trial, water content $15 \mathrm{wt} \%$, fraction 10-4.5 mm.

formed using SBS technology. The relatively high accuracy rates achieved, despite misclassification due to soot-blackened particles, can be explained by the preceding comprehensive biological and mechanical processing as well as by the coarse particle grain size of the examined material, resulting in low amounts of water and adhesives on particle surfaces and enabling mostly correct classification and sorting results.

However, further multiple sorting stages and treatments (cleaning, drying, etc.) will be necessary to meet the requirements of recycling and not only those of WtE.

\section{CONCLUSIONS}

NIR-based SBS trials using pre-treated landfill material show promising results for the application of this technol-

TABLE 2: Yield of PP, PE and PVC products from Halbenrain LFM air-classified heavy fraction - average of 5 runs.

\begin{tabular}{|c|c|c|c|}
\hline & PP product & PE product & PVC product \\
\hline \multirow{2}{*}{ PP yield } & $94.1 \mathrm{p} \%$ & $3.2 \mathrm{p} \%$ & $4.4 p \%$ \\
\hline & $94.8 w t \%$ & $2.1 \mathrm{wt} \%$ & $2.7 w t \%$ \\
\hline \multirow{2}{*}{ PE yield } & $0.8 \mathrm{p} \%$ & $92.9 \mathrm{p} \%$ & $11.0 \mathrm{p} \%$ \\
\hline & $0.6 w t \%$ & 91.8 wt $\%$ & $8.8 w t \%$ \\
\hline \multirow{2}{*}{ PVC yield } & $0.0 \mathrm{p} \%$ & $0.2 \mathrm{p} \%$ & $95.2 \mathrm{p} \%$ \\
\hline & $0.0 w t \%$ & $0.1 w t \%$ & 99.7 wt $\%$ \\
\hline \multirow{2}{*}{ PS yield } & $0.0 p \%$ & $0.8 p \%$ & $0.8 p \%$ \\
\hline & $0.0 w t \%$ & $0.3 w t \%$ & $0.7 w t \%$ \\
\hline \multirow{2}{*}{ PET yield } & $0.0 \mathrm{p} \%$ & $0.0 p \%$ & $0.0 p \%$ \\
\hline & 0.0 wt $\%$ & $0.0 w t \%$ & 0.0 wt\% \\
\hline \multirow{2}{*}{ Residuals yield } & $0.4 p \%$ & $0.4 \mathrm{p} \%$ & $5.1 \mathrm{p} \%$ \\
\hline & $0.3 w t \%$ & 0.2 wt $\%$ & $3.5 w t \%$ \\
\hline
\end{tabular}

ogy in ELFM. The separation of inert and combustibles and the distinction between specific types of waste plastic was successfully demonstrated. Sorting efficiency is affected by the level of pre-processing, the water content and the relative amount of adhesive fines, the material composition and the range of particle sizes of the input material at the SBS stage.

While a decent identification of plastic types (except for soot-blackened plastics) using NIR spectroscopy is possible, detecting pulp-based particles and distinguishing them from inerts was sometimes impaired for particle size ranges $<30 \mathrm{~mm}$ due to adhesive fines, particularly when water was present.

Whether any long-term stability of a sufficiently effective SBS process can be achieved under plausible processing conditions has to be tested at large-scale. Problems, e. g. due to dust formation or various degradation states of plastics, may decrease the efficiency rates attained so far. In such cases it might be necessary to adapt the algorithm for material classification.

\section{REFERENCES}

Beel, H.: Sortierung von schwarzen Kunststoffen nach ihrer Polymerklasse mit Hyperspectral-Imaging-Technologie. In: Thomé-Kozmiensky, K. J: Berliner Recycling- und Rohstoffkonferenz 2017.

Breitenstein, A; Kieckhäfer, K; Spengler, T.: TönsLM - Rückgewinnung von Wertstoffen aus Siedlungsabfall- und Schlackendeponien. In: Recycling und Rohstoffe, Band 9. 2016.

Danthurebandara, M.; van Passel, S.; Vanderreydt, I.; van Acker, K.: Assessment of environmental and economic feasibility of Enhanced Landfill Mining. In: Waste management (New York, N.Y.) 45. 2015. S. 434-447. Doi: 10.1016/j.wasman.2015.01.041.

García López, C.; Küppers, B.; Clausen, A.; Pretz, T.: Landfill Mining. A case study regarding sampling, processing and characterization of excavated waste from an Austrian landfill. In: Detritus 2, 2018. S. 29. Doi: $10.31025 / 2611-4135 / 2018.13664$

García López, C.; Ni, A.; Hernandez Parrodi, J.; Küppers, B.; Raulf, K.; Pretz, T.: Characterization of landfill mining material after ballistic separation to evaluate material and energy recovery. Detritus, 8(1), $5-23$. 
Gundupalli, S.; Hait, S.; Thakur, A.: A review on automated sorting of source-separated municipal solid waste for recycling. In: Waste management (New York, N.Y.) 60. 2017. S. 56-74. Doi: 10.1016/j. wasman.2016.09.015.

Hernández Parrodi J.C.; Raulf K.; Vollprecht D.; Pretz T.; Pomberger R.: Case study on enhanced landfill mining at MSG landfill in Belgium: Mechanical processing of fine fractions for material and energy recovery. In: Detritus 8, 2019. Doi: 10.31025/2611-4135/2019.13877.

Jones, P.; Geysen, D.; Tielemans, Y.; van Passel, S.; Pontikes, Y.; Blanpain, B.: Enhanced Landfill Mining in view of multiple resource recovery. A critical review. In: Journal of Cleaner Production 55. 2013. S. 45-55. Doi: 10.1016/j.jclepro.2012.05.021.

Kieckhäfer, K.; Breitenstein, A.; Spengler, T.: Material flow-based economic assessment of landfill mining processes. In: Waste management (New York, N.Y.) 60. 2017. S. 748-764. Doi: 10.1016/j. wasman.2016.06.012.

Krook, J.; Svensson, N.; Eklund, M.: Landfill mining. A critical review of two decades of research. In: Waste management (New York, N.Y.) 32 (3). 2012. S. 513-520. Doi: 10.1016/j.wasman.2011.10.015.

Mor, S.; Ravindra, K.; de Visscher, A.; Dahiya, R.; Chandra, A.: Municipal solid waste characterization and its assessment for potential methane generation. A case study. In: The Science of the total environment 371 (1-3). 2006. S. 1-10. Doi: 10.1016/j.scitotenv.2006.04.014.

Pomberger, R.; Küppers, B. (2017): Entwicklungen in der sensorgestützten Sortiertechnik. In: Österreichische Abfallwirtschaftstagung 2017.
Pretz, T.; Julius, J.: Stand der Technik und Entwicklung bei der berührungslosen Sortierung von Abfällen. In: Österreichische Abfallwirtschaftstagung 60 (7-8). 2008. S. 105-112.

Quaghebeur, M.; Laenen, B.; Geysen, D.; Nielsen, P.; Pontikes, Y.; van Gerven, T.; Spooren, J.: Characterization of landfilled materials. Screening of the enhanced landfill mining potential. In: Journal of Cleaner Production 55. 2013. S. 72-83. Doi: 10.1016/j.jclepro.2012.06.012

Rotheut, M.; Quicker, P.: Energetic utilisation of refuse derived fuels from landfill mining. In: Waste management (New York, N.Y.) 62. 2017. S. 101-117. Doi: 10.1016/j.wasman.2017.02.002.

Sormunen, K.; Ettala, M.; Rintala, J.: Detailed Internal Characterisation of Two Finnish Landfills by Waste Sampling. In: Waste management (New York, N.Y.) 28. 2008. Doi: 10.1016/j.wasman.2007.01.003.

Wolfsberger, T., Aldrian, A., Sarc, R., Hermann, R., Höllen, D., Budischowsky, A., Zöscher, A., Ragoßnig, A. \& Pomberger, R.: LANDFILL MINING: Resource potential of Austrian landfills - Evaluation and quality assessment of recovered MSW by chemical analyses. In: Waste Management \& Research, 2015. S. 962-974. DOI:10.1177/0734242X15600051.

Wörrle, J.: Immer mehr Bauabfälle: Deponien am Limit. In: DeutscheHandwerksZeitung. 2018.

Zhou, C.; Fang, W.; Xu, W.; Cao, A.; Wang, R.: Characteristics and the recovery potential of plastic wastes obtained from landfill mining. In: Journal of Cleaner Production 80. 2014. S. 80-86. Doi: 10.1016/j. jclepro.2014.05.083. 